Fifth International Conference on Sustainable Construction Materials and

Technologies. http://www.claisse.info/Proceedings.htm

\title{
THE USE OF STEEL FIBERS TO ENHANCE THE PERFORMANCE OF CONCRETE MADE WITH RECYCLED AGGREGATE
}

\author{
Nancy Kachouh ${ }^{1}$, Hilal El-Hassan ${ }^{2}$, and Tamer El Maaddawy ${ }^{3}$ \\ ${ }^{1}$ Department of Civil and Environmental Engineering, UAE University, Al Ain, UAE, \\ P.O. Box 15551, nancy.kachouh@uaeu.ac.ae \\ ${ }^{2}$ Department of Civil and Environmental Engineering, UAE University, Al Ain, UAE, \\ P.O. Box 15551, helhassan@uaeu.ac.ae (corresponding/presenting author) \\ ${ }^{3}$ Department of Civil and Environmental Engineering, UAE University, Al Ain, UAE, \\ P.O. Box 15551, tamer.maaddawy@uaeu.ac.ae
}

\section{CATEGORY}

Efficient \& Sustainable Use of Construction Materials.

\begin{abstract}
This research investigates the effect of replacing natural coarse aggregates with recycled concrete aggregates (RCA) on the performance of normal-strength (30 $\mathrm{MPa}$ ) concrete. To promote $100 \%$ replacement, steel fibers were incorporated at $0-2 \%$, by volume $\left(\mathrm{v}_{\mathrm{f}}\right)$. Locally-abundant dune sand served as sustainable fine aggregates. Physical, rheological, and mechanical properties were evaluated through experimental testing, including slump, density, compressive strength, and flexural strength. Results of plain concrete showed that an increase in RCA replacement led to a decrease in density and slump. The addition of steel fibers increased the density but decreased the slump. Compared to the control sample, the compressive and flexural strengths decreased by 18 and $51 \%$ with $100 \%$ RCA replacement. The incorporation of $2 \%$ steel fibers could restore the former by $90 \%$ and nearly doubled the latter. Findings provide evidence on the feasibility of producing steel fiber-reinforced normal-strength concrete with $100 \%$ RCA that is suitable for structural applications.
\end{abstract}

Keywords: Steel fibers, concrete, recycled aggregate, normal strength concrete, 


\section{INTRODUCTION}

The construction industry is held accountable for major disturbance in the environment and ecology. Environmentalists and scientists advocate the reduction of construction materials, including concrete. Yet, the ever increasing population is causing an increase in the production of concrete, resulting in an increase in the demand for its components, namely natural aggregates. Additionally, aging infrastructures and superstructures creates a large quantity of construction and demolition waste $(C \& D)$ that is dumped in landfills, causing serious environmental hazards. The limited space for landfills and the scarcity of natural resources of aggregates call attention to the concept of recycling concrete waste to manufacture recycled concrete aggregates (RCA) as a potential substitute of natural aggregates (NA) (Radonjanin et al., 2013). The use of RCA in the production of concrete is still limited to non-structural application such as roadway subbase, as the lower quality of RCA compared to NA results in a decrease in the concrete mechanical performance (Wagih et al., 2013, Rao et al., 2007, Etxeberria et al., 2007).

Various studies have investigated the effect of RCA on the performance of concrete products. Most researchers reported lower strength and elastic modulus and higher water absorption and porosity upon the replacement of NA by RCA in concrete (Meyer, 2009, Casuccio et al., 2008, de Juan and Gutiérrez, 2009, Debieb et al., 2010). In his study, Çakır (2014) concluded that the replacement of NA by $100 \%$ of RCA resulted in a decrease in the concrete compressive strength by $24 \%$. Malešev et al. (2010) noted that the bulk density of fresh concrete, wear resistance, and modulus of elasticity decreased with the increase in the RCA replacement percentage. Further, the use of RCA obtained from crushing higher strength concrete had no influence on the compressive strength.

Several solutions have been proposed to compensate the reduction in strength resulting from the use of RCA in concrete such as increasing the cement content, reducing the water-to-cement ratio, adding fly ash, removing or strengthening the old adhered mortar attached to the RCA and adding steel fibers (Radonjanin et al., 2013, Malešev et al., 2010, Tabsh and Abdelfatah, 2009, Corinaldesi, 2010). Tam et al. (2007) proposed a new mixing technique: the two-stage mixing approach. This technique consisted of a new sequence of mixing concrete ingredients. Experimental results showed that this mixing approach could enhance the compressive and tensile strength of RCA concrete by up to $22 \%$ compared to a normal mixing approach. Past research has also investigated the effect of adding steel fibers on RCA concrete mixes. Carneiro et al. (2014), studied the effect of adding $\mathrm{v}_{\mathrm{f}}$ of $0.75 \%$ of steel fibers (SF) in the concrete mix made of $25 \%$ replacement percentage of RCA. The results indicated an increase in the compressive strength and improvement in the failure mechanism compared to normal concrete. It is worth mentioning that the majority of past work altered mixture proportions to attain a target design compressive strength and slump (Gao et al., 2017a, Gao et al., 2017b).

This paper presents a cutting edge material characterization of concrete made of recycled aggregate with the addition of steel fibers. RCA were obtained from a local 
concrete waste company that crushes old concrete structures with unknown compressive strength. RCA were used without any treatment to provide a more practical approach that promotes the use of RCA in its as-received conditions. In previous work, natural fine aggregates had been used with coarse recycled aggregates; however, in this project locally-abundant desert dune sand was employed as a sustainable alternative to natural fine aggregates. Concrete mixes were designed for a 28-day concrete cylinder compressive strength of $30 \mathrm{MPa}$ without altering mixture components. NA was replaced by RCA in the order of 30, 70, and $100 \%$, by mass. Steel fibers were added in the order of 1 and $2 \%$, by volume, to RCA concrete mixes. The combined effect of RCA replacement and steel fiber incorporation was investigated against slump, density, compressive strength and flexural strength.

\section{MATERIALS AND METHODS}

The combined effect of recycled aggregate and steel fiber on the slump, density, compressive strength and flexural strength of concrete was investigated using a total of 10 mixes. The mixes were designed and prepared by using different proportions of NA, RCA and steel fibers (SF). Experiments were carried out on 100 x $200 \mathrm{~mm}$ cylinders (diameter and height) and $100 \times 100 \times 500$ mm prisms (width, height and length).

Table 1. Physical properties of fine and coarse aggregates

\begin{tabular}{|l|l|l|l|l|l|l|l|}
\hline Property & $\begin{array}{l}\text { Unit } \\
\text { Weight }\end{array}$ & $\begin{array}{l}\text { Water } \\
\text { absorption }\end{array}$ & $\begin{array}{l}\text { LA } \\
\text { abrasion }\end{array}$ & $\begin{array}{l}\text { Surface } \\
\text { area }\end{array}$ & $\begin{array}{l}\text { Soundness } \\
\left(\mathrm{MgSO}_{4}\right)\end{array}$ & $\begin{array}{l}\text { Specific } \\
\text { gravity }\end{array}$ & $\begin{array}{l}\text { Fineness } \\
\text { modulus }\end{array}$ \\
\hline Unit & $\mathrm{kg} / \mathrm{m}^{3}$ & $\%$ & $\%$ & $\mathrm{~cm}^{2} / \mathrm{g}$ & $\%$ & - & - \\
\hline ASTM & $\mathrm{C} 29$ & $\mathrm{C} 127$ & $\mathrm{C} 131$ & $\mathrm{C} 136$ & $\mathrm{C} 88$ & $\mathrm{C} 127$ & $\mathrm{C} 136$ \\
\hline NA & 1635 & 0.22 & 16.0 & 2.49 & 1.20 & 2.82 & 2.46 \\
\hline RCA & 1563 & 6.63 & 32.6 & 2.50 & 2.78 & 2.63 & 2.53 \\
\hline Dune Sand & 1663 & 19.92 & - & 116.8 & - & 2.77 & 2.42 \\
\hline
\end{tabular}

\section{Materials}

The materials used in the present investigation include ASTM type I ordinary Portland cement as binder, locally-abundant desert dune sand as sustainable fine aggregate, coarse aggregate that included NA and RCA, and tap water for mixing and curing. NA was obtained as crushed limestone with a nominal maximum particle size (NMS) of 19 $\mathrm{mm}$. RCA was obtained from a local concrete recycling plant with a NMS of $25 \mathrm{~mm}$. It is worth mentioning that RCA were obtained from crushing old concrete structures with unknown compressive strength and the plant did not perform any treatments. The Particle size distribution of cement and dune sand are shown in Figure 1. The gradation curves of NA and RCA, illustrated in Figure 2, were within the upper and lower limit bounds specified by ASTM C33 (ASTM, 2016a). The detailed properties of NA, RCA and dune sand along with the corresponding ASTM standard tests are shown in Table 1. The RCA and NA were used in saturated surface dry (SSD) condition to account for their water absorption. The SF used in this study were hooked at both ends with a tensile strength of $1345 \mathrm{~N} / \mathrm{mm}^{2}$, Young's modulus of $210000 \mathrm{~N} / \mathrm{mm}^{2}$, mean diameter $\left(\mathrm{d}_{\mathrm{f}}\right)$ of $0.55 \mathrm{~mm}$, mean length $\left(\mathrm{l}_{\mathrm{f}}\right)$ of $35 \mathrm{~mm}$, and an aspect ratio $\left(\mathrm{l}_{\mathrm{f}} / \mathrm{d}_{\mathrm{f}}\right)$ of 65 . 


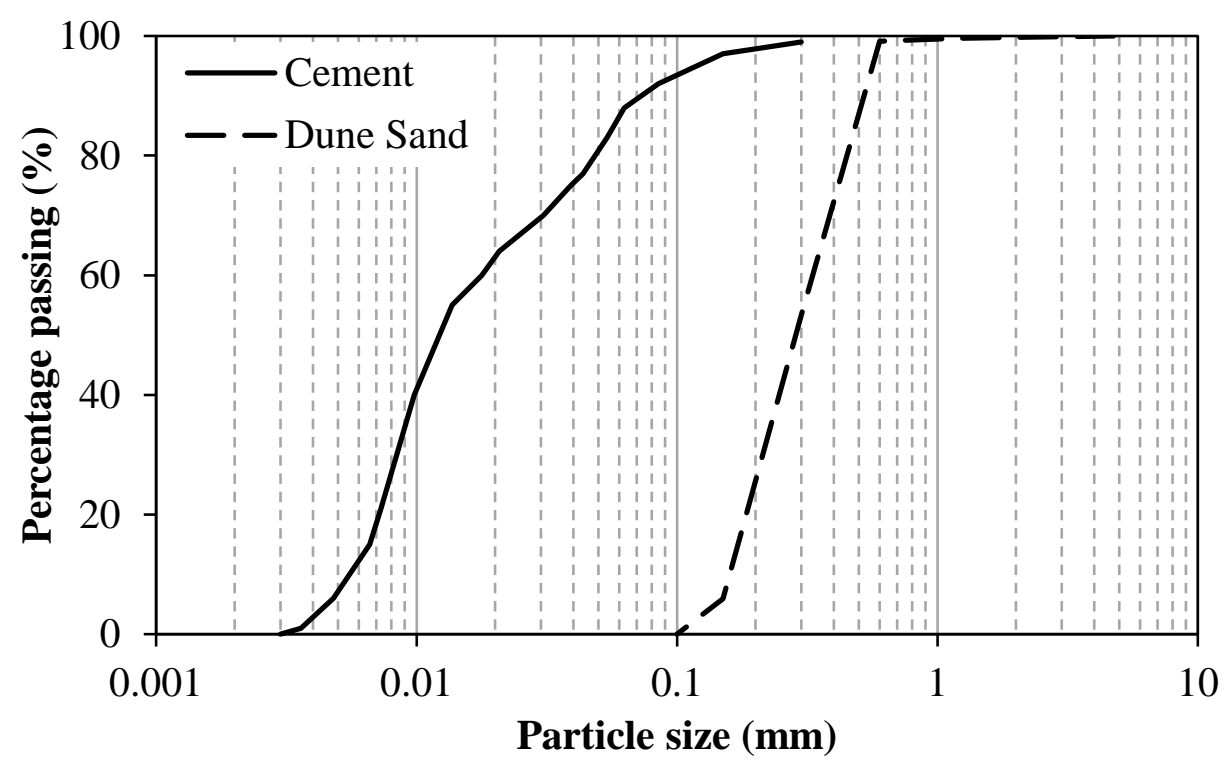

Figure 1. Particle size distribution of cement and dune sand

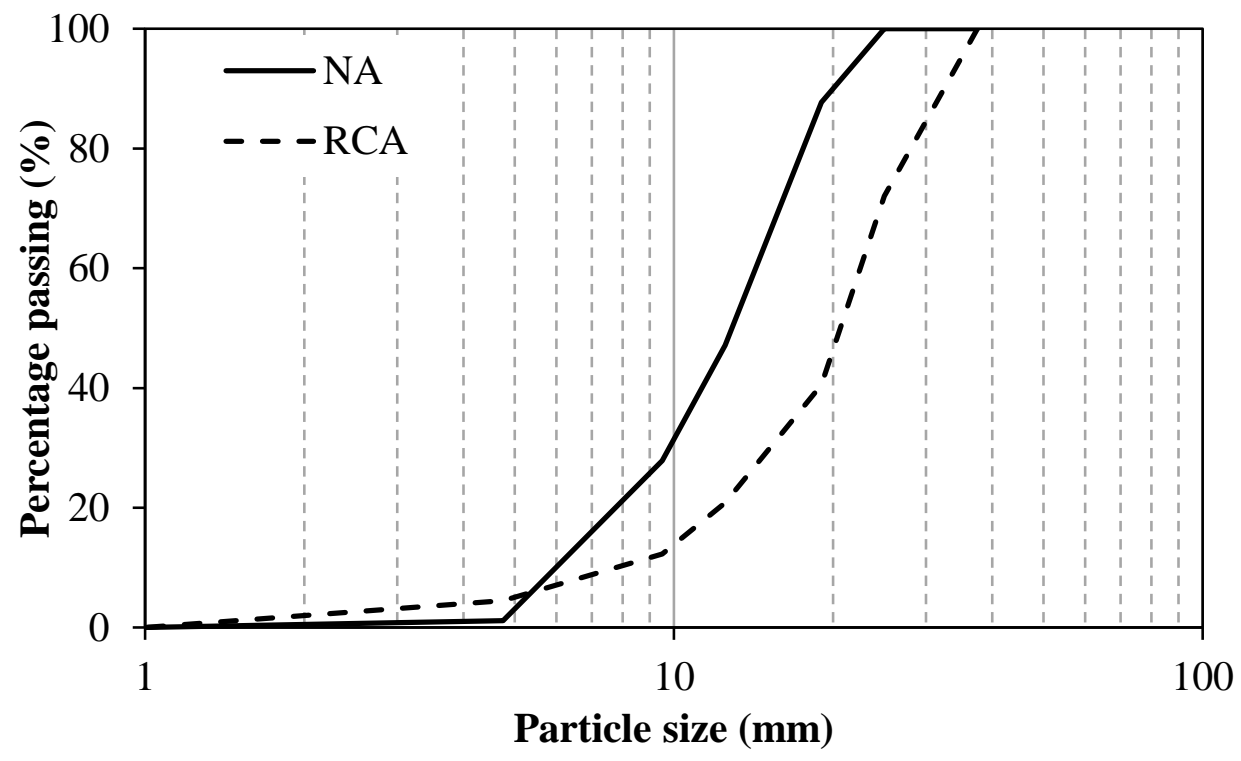

Figure 2. Particle size distribution of different mixes of NA and RCA

\section{Mixture Proportioning}

The mix design utilized in this study is based on ACI 211.1 (2002), considering a cylindrical concrete compressive strength $\left(\mathrm{f}^{\prime} \mathrm{c}\right)$ of $30 \mathrm{MPa}$ for the control mix. The resulting control mix consisted of coarse aggregate, cement, dune sand, and water-tocement ratio of $1130 \mathrm{~kg} / \mathrm{m}^{3}, 470 \mathrm{~kg} / \mathrm{m}^{3}, 570 \mathrm{~kg} / \mathrm{m}^{3}$, and 0.49 , respectively. Other than the type of aggregate used and volumetric addition of steel fibers, these components were kept constant for all mixes. Table 2 indicates the percentages of NA, RCA, and 
SF for each mix. Mixes were labeled RxFy, where $x$ denoted the percentage of RCA and $y$ indicated the steel fiber volume fraction. R0F0 is the control mix designation.

\section{Sample Preparation}

Concrete components were mixed using a laboratory mechanical mixer. Coarse aggregates and SF were first mixed for 3 minutes to ensure the SF were well dispersed. The cement and dune sand were then added and mixed for another 2 minutes. Water was gradually added to the dry components and mixed for 2 more minutes to ensure a homogenous and uniform mixture. The slump of fresh concrete was tested right after the mixing process. The specimens were cast in designated molds, compacted on a vibration table and covered with plastic sheets for 24 hours. Specimens were then demolded and placed in a water tank for moist curing until the time of testing. For each test, three replicate specimens were prepared.

Table 2. Mix proportions of concrete mixes with different aggregate and steel fiber combinations

\begin{tabular}{|l|l|l|l|l|}
\hline \multirow{2}{*}{ Mix No. } & Mix Designation & RCA & NA & Steel Fibers \\
\cline { 3 - 5 } & R0F0 & 0 & 100 & 0 \\
\hline 2 & R30F0 & 30 & 70 & 0 \\
\hline 3 & R70F0 & 70 & 30 & 0 \\
\hline 4 & R100F0 & 100 & 0 & 0 \\
\hline 5 & R30F1 & 30 & 70 & 1 \\
\hline 6 & R70F1 & 70 & 30 & 1 \\
\hline 7 & R100F1 & 100 & 0 & 1 \\
\hline 8 & R30F2 & 30 & 70 & 2 \\
\hline 9 & R70F2 & 70 & 30 & 2 \\
\hline 10 & R100F2 & 100 & 0 & 2 \\
\hline
\end{tabular}

\section{Performance Evaluation}

The experimental program included tests on more than 100 specimens to identify physical, rheological, and mechanical properties of different concrete mixes. Fresh concrete slump was measured following the ASTM C143 standards (ASTM, 2015b) to evaluate the effect of RCA replacement and SF incorporation on the workability of concrete mixes. The 28-day hardened $\left(\rho_{\mathrm{h}}\right)$ concrete density was determined according to ASTM C642 (ASTM, 2013) procedure. Compressive strength test was performed on concrete cylinders at 3, 7, and 28 days, in accordance with ASTM C39 (ASTM, 2015a). An electro-hydraulic servo-controlled machine was used with a capacity of $2000 \mathrm{kN}$. Axial loads were applied at a loading rate of $7 \mathrm{kN} / \mathrm{s}$. Rectangular standard prism $100 \times 100 \times 500 \mathrm{~mm}$ (width, height and length) specimens were tested after 28 days from cast to evaluate the flexural performance according to ASTM C78 (ASTM, $2016 \mathrm{~b}$ ). The prisms were supported symmetrically over a span of $450 \mathrm{~mm}$ and subjected to four-point loading till failure of the specimen. 


\section{EXPERIMENTAL RESULTS AND DISCUSSION}

\section{Slump}

The workability of fresh concrete mixes was characterized by measuring the slump. It is noteworthy to mention that the cement content, water content and water-to-cement ratio were not adjusted to obtain a desired compressive strength or slump. To ensure that the aggregates will not absorb any mixing water, they were used in surfacesaturated dry (SSD) condition. The results of fresh concrete slump are illustrated in Figure 3. The slump of the control mix was found to be equal to $150 \mathrm{~mm}$ which is $14 \%$ lower than the slump used in the design procedure of ACI 211.1 [29]. This is attributed to the use of dune sand as a sustainable alternative to typical fine aggregates. Its larger surface area and higher air and fine particles contents negatively affected the workability of concrete mixes. Further, it can be noted that the increase in RCA replacement percentage from $0 \%$ to $100 \%$ caused a decrease in workability by $37 \%$. This reduction in workability is attributed to the rough surface texture and irregular geometric shape of RCA. The effect of SF on the workability of concrete mixes was also investigated. Compared to the control mix R0F0, the slump decreased by 43 and $87 \%$ upon the respective addition of 1 and $2 \% \mathrm{SF}$, by volume, to the mix made of $100 \%$ RCA. This is attributed to insufficient amount of cement paste to cover the steel fibers in the concrete mixes. Thus, it can be concluded that RCA replacement percentage had a less severe impact on workability than SFs incorporation.

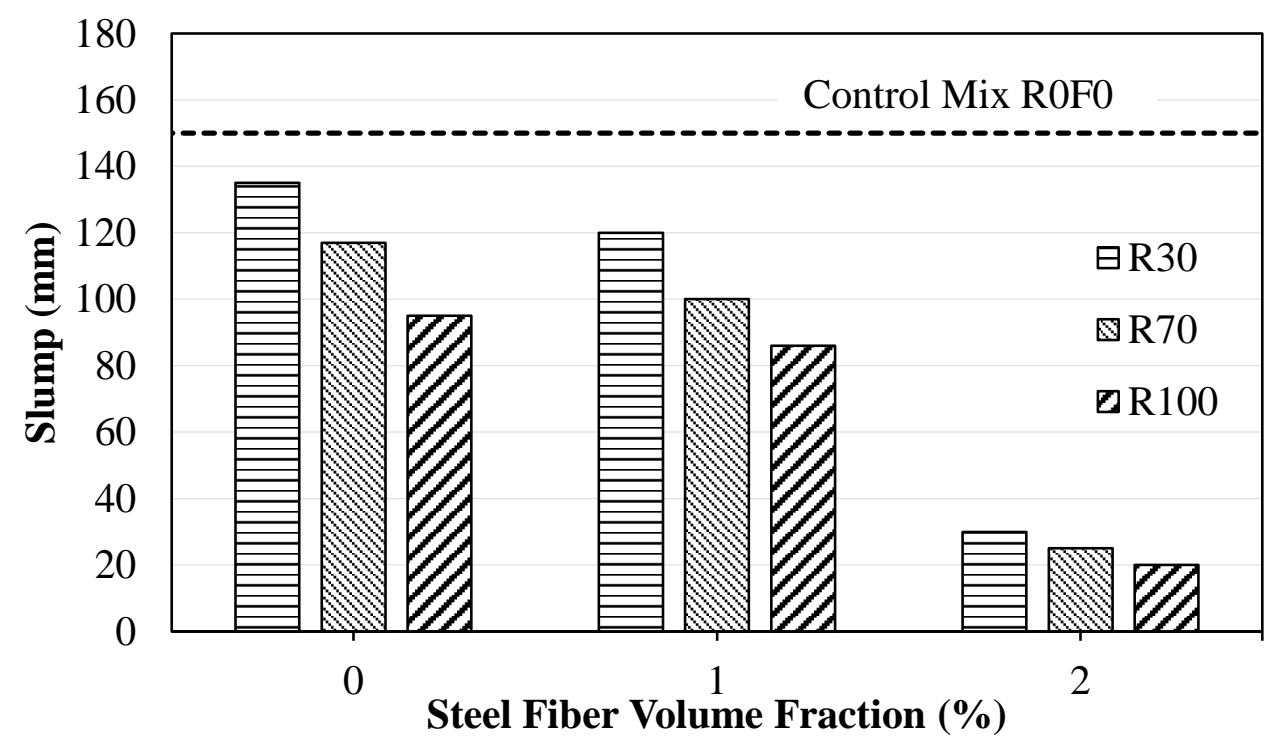

Figure 3. Slump of concrete mixes with different RCA and SF combinations

\section{Concrete Density}

The hardened 28-day density of concrete mixes made of different proportions of RCA, NA and SFs is illustrated in Figure 4. It was evident from the findings that the increase in RCA replacement percentage resulted in a reduction in concrete density. The use of $100 \%$ RCA resulted in a $14 \%$ decrease in density compared to the control mix R0F0. This reduction in density is attributed to the lower bulk density of the RCA compared to NA, as displayed in Table 2. However, the addition of SFs resulted in an increase in 
concrete density with the highest increase of $2.8 \%$ in mix R30F2 compared to the control mix R0F0. Nevertheless, the replacement of NA by RCA reduced the hardened density of steel fiber-reinforced concrete.

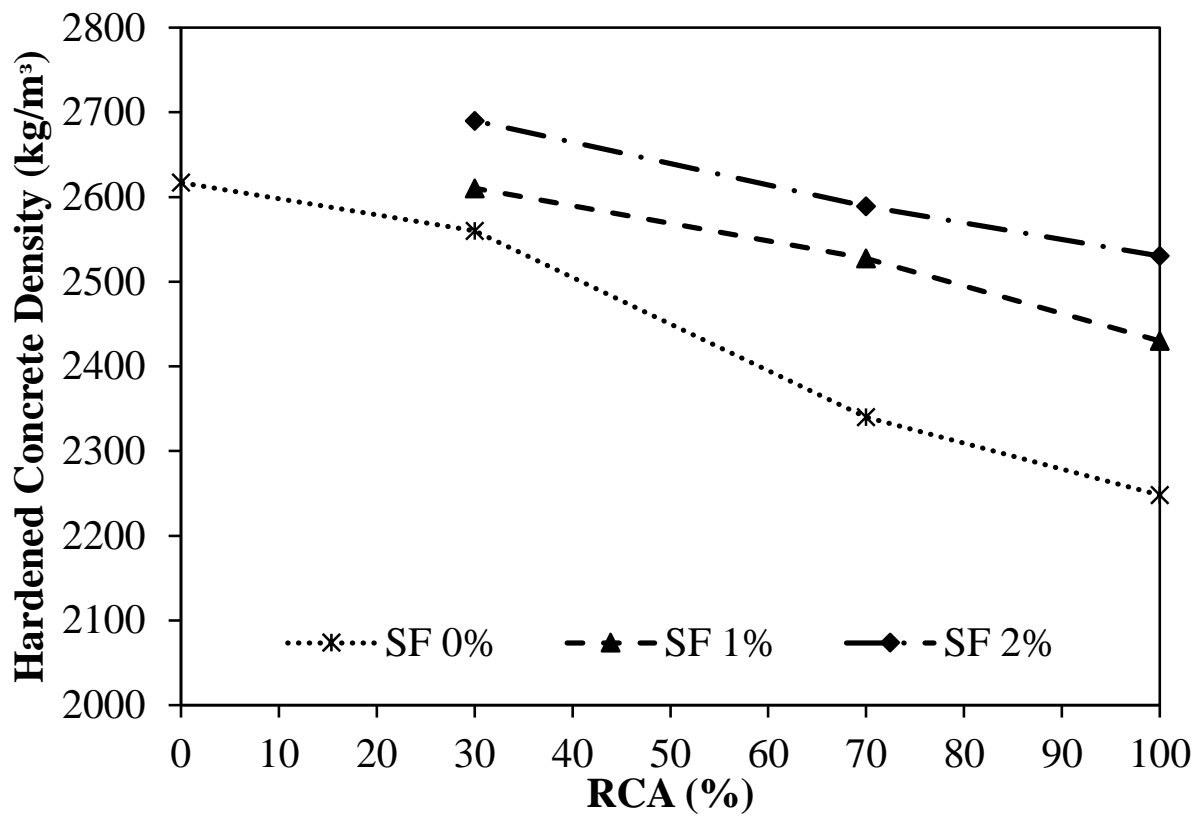

Figure 4. Hardened concrete density of concrete mixes with different RCA and SF combinations

\section{Compressive Strength}

The concrete compressive strength measured at 3,7 and 28 days of concrete mixes made of different proportions of RCA, NA and SFs is shown in Figure 5. Due to the continuous hydration reaction, all mixes exhibited similar strength development over time. Though, it was clear that the increase in RCA had a negative effect on the concrete compressive strength. It is worth mentioning that the experimental compressive strength of the control mix R0F0 was found to be $36.4 \mathrm{MPa}$, which is $21 \%$ higher than the designed compressive strength of $30 \mathrm{MPa}$ following ACI 211.1 [29] procedure. Apparently, the use of dune sand as sustainable replacement of fine aggregate made the concrete denser, thus, contributing to the increase in compressive strength with respect to the design strength. Experimental results also show that mix R30F0 made of 30\% RCA exceeded the target compressive strength of $30 \mathrm{MPa}$. Further replacement of RCA at $100 \%$ in mix $\mathrm{R} 100 \mathrm{~F} 0$ resulted in a reduction in compressive strength by $18 \%$ in comparison with the design compressive strength of $30 \mathrm{MPa}$. This is mainly due to the porous structure of RCA and the weak interface zone between old mortar attached to RCA and the new paste. While the main purpose of adding steel fibers was not primary to increase the concrete compressive strength, their effect on concrete properties has been noted. The addition of steel fibers in volume fractions of 1 and $2 \%$ to mixes made of $30 \%$ RCA resulted in respective compressive strengths of 32 and $33.1 \mathrm{MPa}$, thus, exceeding that of the design. Mixes made of $70 \%$ RCA with similar steel fiber volume fractions attained up to $95 \%$ and $98 \%$ of the design strength of $30 \mathrm{MPa}$, respectively. Steel fibers were also added, in volume fraction up to $2 \%$, to mixes made of $100 \%$ RCA. The resulting concretes attained approximately $90 \%$ of the design strength of 30 
MPa. It is clear that adding steel fibers to mixes made of different proportions of RCA made the concrete denser, provided better integrity due to their bridging effect, and improved the concrete performance by reducing the development of microcracks (Gao et al., 2017a). Thus, it could be concluded that the RCA percentage of $30 \%$ could replace NA in producing concrete without loss in compressive strength. The RCA percentages of $70 \%$ and $100 \%$ could replace NA in producing concrete mixes made with desert dune sand and $\mathrm{v}_{\mathrm{f}}$ of 1 and $2 \%$ with limited loss in compressive strength $(\leq$ $10 \%)$.

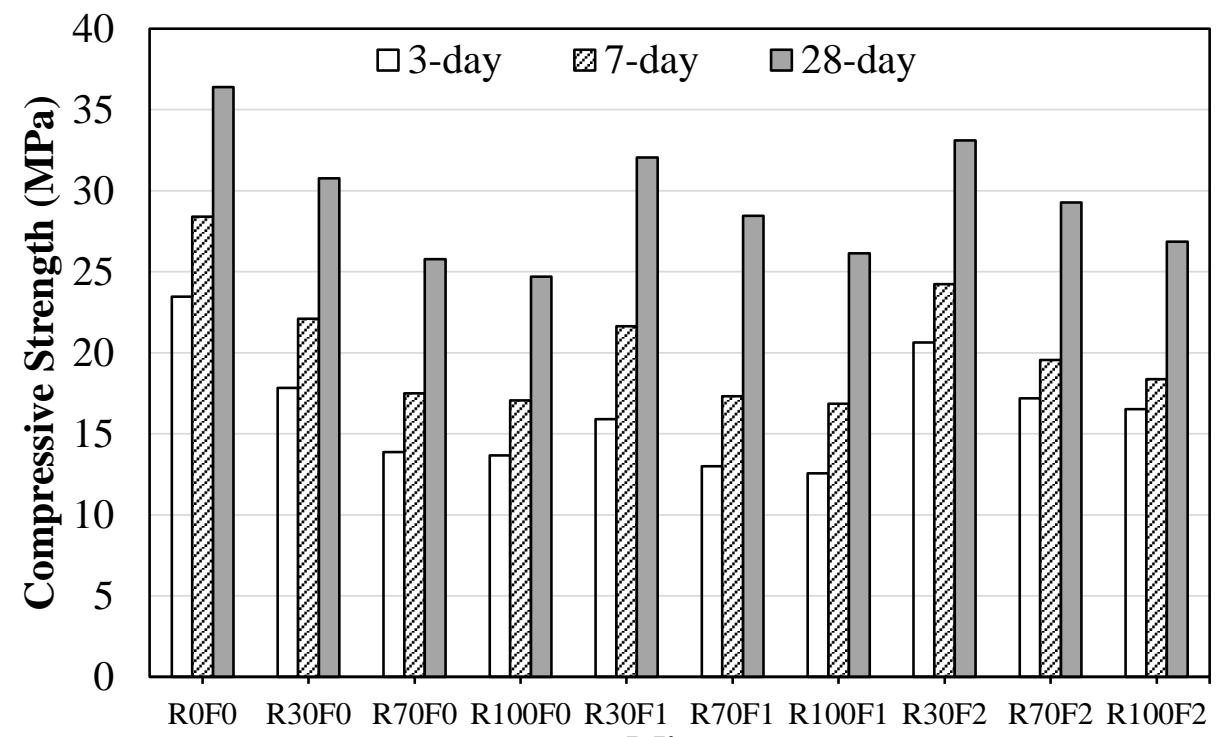

Mixes

Figure 5. Compressive strength of concrete mixes with different RCA and SF combinations

\section{Flexural Strength}

The flexural strength was determined as the peak stress in the stress-deflection curves of 28-day concretes. The flexural strength was calculated by Eq. (1), where $\mathrm{f}$ is flexural strength (MPa), $\mathrm{F}$ is the load corresponding to specified deflection $(\mathrm{N}), \mathrm{b}$ is the width $(\mathrm{mm}), \mathrm{h}$ is the height of specimen $(\mathrm{mm})$, and $\mathrm{l}$ is the span length of specimen $(\mathrm{mm})$. The flexural strength of different concrete mixes, presented in Figure 6, show that the replacement of $30 \%, 70 \%$ and $100 \%$ RCA resulted in a respective $16 \%, 46 \%$ and $51 \%$ decrease in flexural strength. This is mainly due to the lower strength of RCA, the higher percentage of voids, and the weak interface zone available between the old adhered mortar and the new mortar. Further, the addition of steel fibers led to an increase in flexural strength. A similar trend was reported by Gao and Zhang (2018). Their effect was highest in concrete mixes made with 100\% RCA, with 1 and $2 \%$ volume fractions increasing the flexural strength by 96 and $160 \%$, respectively, compared to the plain concrete mix R0F0. This is attributed to the fact that the steel fibers arrest micro cracks due to their bridging effect in concrete. It is also worth noting that the negative impact of RCA had become less prominent in steel fiber-reinforced concrete mixes. In fact, the loss upon the replacement of 70 and 100\% RCA was, on average, 3.9 and $6.6 \%$, respectively. From Figure 6, it is clear that the RCA could 
replace NA by $100 \%$ in producing concrete mixes made with desert dune sand and $\mathrm{v}_{\mathrm{f}}$ of $1 \%$ with insignificant loss in flexural strength $(<4 \%)$. Results of concretes made with $2 \%$ steel fibers and $100 \%$ RCA exceed those of the control mix.

$\mathrm{f}=\frac{\mathrm{FL}}{\mathrm{bh}^{2}}$

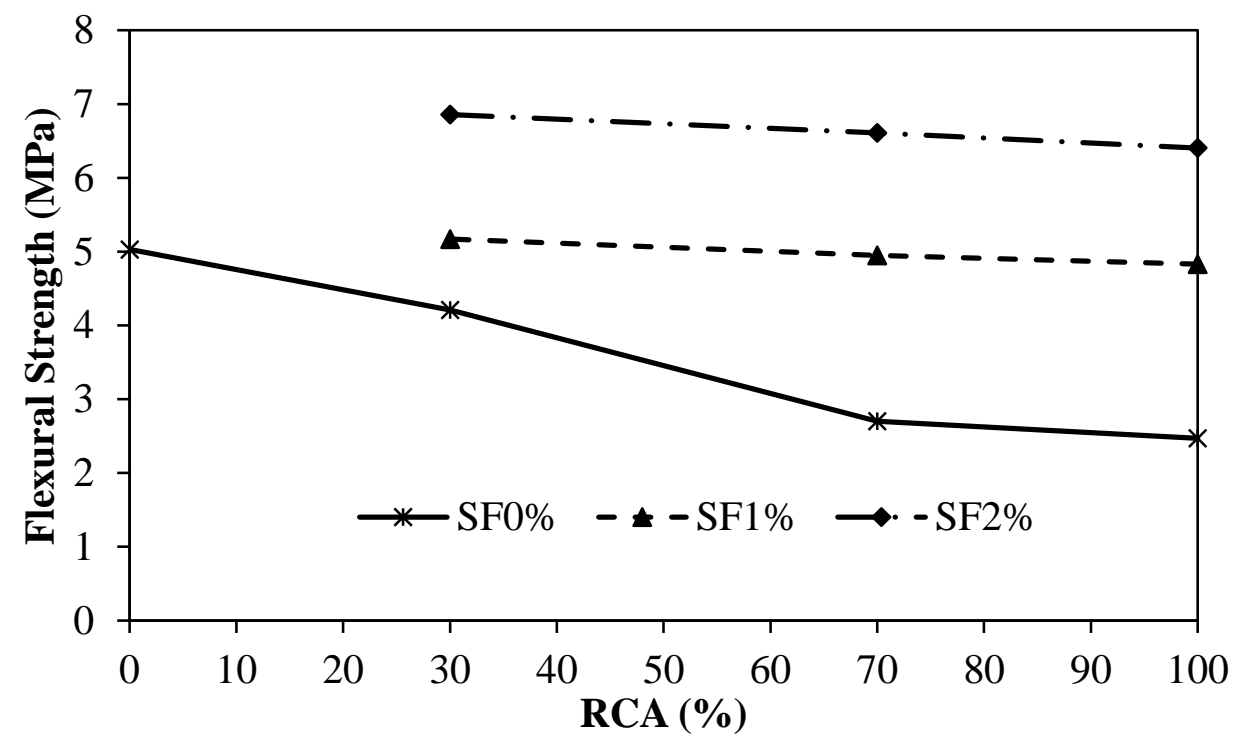

Figure 6. Flexural strength of concrete mixes with different RCA and SF combinations

\section{CONCLUSIONS}

This paper highlights the combined effect of steel fibers and recycled concrete aggregates on the performance of concrete mixes made of dune sand as a sustainable alternative to natural fine aggregate. Experimental testing program was conducted on cylinders and prisms to assess the workability, density, compressive strength and flexural strength. Based on the tests results, the following conclusions can be drawn:

- Concrete workability (slump) decreased as the RCA replacement percentage increased. This is mainly due to the existing mortar attached to RCA creating a rough and porous surface that increased the air content. The addition of steel fibers resulted in further reduction in slump, as not enough paste was available to cover the steel fibers in the concrete mixes.

- Hardened concrete density decreased as the RCA replacement percentage increased in the concrete mixes. This is attributed to the lower bulk density of RCA. The addition of steel fibers resulted in an increase in concrete density.

- The increase in the RCA replacement percentage resulted in a reduction in the cylindrical concrete compressive strength. This mainly due to the porous structure of RCA and the week interface zone between old mortar attached to RCA and the new paste. The addition of $\mathrm{v}_{\mathrm{f}} 1$ and $2 \%$ steel fibers resulted in an increase in the compressive strength, owing to the densification of the concrete structure. Concrete mixes made of $30 \%$ RCA produced concrete without loss 
in compressive compared to the design compressive strength of $30 \mathrm{MPa}$. Concrete mixes made of $70 \%$ and $100 \%$ RCA produced concrete with limited loss in compressive strength $(\leq 10 \%)$ with the addition of $\mathrm{v}_{\mathrm{f}}$ of 1 and $2 \%$ steel fibers, respectively.

- The flexural strength decreased with the increase of RCA replacement percentage. The addition of steel fibers resulted in a significant increase in the flexural strength of concrete mixes made of different percentages of RCA.

\section{ACKNOWLEDGEMENTS}

This project is supported by the United Arab Emirates University (UAEU) under grant number $31 \mathrm{~N} 258$. The contributions of the UAEU engineers and staff are greatly appreciated.

\section{REFERENCES}

ACI 211.1 (2002). "Standard practice for selecting proportions for normal, heavyweight, and mass concrete ". Farmington Hills, Michigan.: American Concrete Institute.

ASTM (2013). "Standard test method for density, absorption, and voids in hardened concrete". C642. West Conshohocken, PA: ASTM International.

$\operatorname{ASTM}$ (2015a). "Standard test method for compressive strength of cylindrical concrete specimens". C39. West Conshohocken, PA: ASTM.

ASTM (2015b). "Standard test method for slump of hydraulic-cement concrete". C143. West Conshohocken, PA: ASTM International.

ASTM (2016a). "Standard specification for concrete aggregates". C33. West Conshohocken, PA: ASTM International.

ASTM (2016b). "Standard test method for flexural strength of concrete (using simple beam with third-point loading)". C78. West Conshohocken, PA: ASTM International.

Çakır, Ö. (2014). "Experimental analysis of properties of recycled coarse aggregate (rca) concrete with mineral additives." Construction and Building Materials, $68,17-25$

Carneiro, J. A., Lima, P. R. L., Leite, M. B. \& Toledo Filho, R. D. (2014). "Compressive stress-strain behavior of steel fiber reinforced-recycled aggregate concrete." Cement and Concrete Composites, 46, 65-72.

Casuccio, M., Torrijos, M. C., Giaccio, G. \& Zerbino, R. (2008). "Failure mechanism of recycled aggregate concrete." Construction and Building Materials, 22, $1500-1506$.

Corinaldesi, V. (2010). "Mechanical and elastic behaviour of concretes made of recycled-concrete coarse aggregates." Construction and Building Materials, 24, 1616-1620.

de Juan, M. S. \& Gutiérrez, P. A. (2009). "Study on the influence of attached mortar content on the properties of recycled concrete aggregate." Construction and Building Materials, 23, 872-877. 
Debieb, F., Courard, L., Kenai, S. \& Degeimbre, R. (2010). "Mechanical and durability properties of concrete using contaminated recycled aggregates." Cement and Concrete Composites, 32, 421-426.

Etxeberria, M., Vázquez, E., Marí, A. \& Barra, M. (2007). "Influence of amount of recycled coarse aggregates and production process on properties of recycled aggregate concrete." Cement and Concrete Research, 37, 735-742.

Gao, D. \& Zhang, L. (2018). "Flexural performance and evaluation method of steel fiber reinforced recycled coarse aggregate concrete." Construction and Building Materials, 159, 126-136.

Gao, D., Zhang, L. \& Nokken, M. (2017a). "Compressive behavior of steel fiber reinforced recycled coarse aggregate concrete designed with equivalent cubic compressive strength." Construction and Building Materials, 141, 235-244.

Gao, D., Zhang, L. \& Nokken, M. (2017b). "Mechanical behavior of recycled coarse aggregate concrete reinforced with steel fibers under direct shear." Cement and Concrete Composites, 79, 1-8.

Malešev, M., Radonjanin, V. \& Marinković, S. (2010). "Recycled concrete as aggregate for structural concrete production." Sustainability, 2, 1204.

Meyer, C. (2009). "The greening of the concrete industry." Cement and Concrete Composites, 31, 601-605.

Radonjanin, V., Malešev, M., Marinković, S. \& Al Malty, A. E. S. (2013). "Green recycled aggregate concrete." Construction and Building Materials, 47, 15031511.

Rao, A., Jha, K. N. \& Misra, S. (2007). "Use of aggregates from recycled construction and demolition waste in concrete." Resources, Conservation and Recycling, 50, 71-81.

Tabsh, S. W. \& Abdelfatah, A. S. (2009). "Influence of recycled concrete aggregates on strength properties of concrete." Construction and Building Materials, 23, 1163-1167.

Tam, V. W. Y., Tam, C. M. \& Wang, Y. (2007). "Optimization on proportion for recycled aggregate in concrete using two-stage mixing approach." Construction and Building Materials, 21, 1928-1939.

Wagih, A. M., El-Karmoty, H. Z., Ebid, M. \& Okba, S. H. (2013). "Recycled construction and demolition concrete waste as aggregate for structural concrete." HBRC Journal, 9, 193-200. 